Article

\title{
Seasonal Contrast and Interactive Effects of Potential Drivers on Land Surface Temperature in the Sichuan Basin, China
}

\author{
Ziyi Wang ${ }^{1,+}{ }^{+}$, Dongqi Sun ${ }^{2, *} \mathbb{C}$, Chunguang $\mathrm{Hu}^{3,+}$, Yu Wang ${ }^{1}$ and Jingxiang Zhang ${ }^{1}$ \\ 1 School of Architecture and Urban Planning, Nanjing University, Nanjing 210093, China; \\ wangziyi1011@smail.nju.edu.cn (Z.W.); mg20360050@smail.nju.edu.cn (Y.W.); \\ jingxiangzhang@nju.edu.cn (J.Z.) \\ 2 Institute of Geographic Sciences and Natural Resources Research, Chinese Academy of Sciences, \\ Beijing 100101, China \\ 3 School of Architecture and Urban Planning, Huazhong University of Science and Technology, \\ Wuhan 430074, China; huchunguang@hust.edu.cn \\ * Correspondence: sundq@igsnrr.ac.cn \\ + These authors contributed equally to this work.
}

check for updates

Citation: Wang, Z.; Sun, D.; Hu, C.; Wang, Y.; Zhang, J. Seasonal Contrast and Interactive Effects of Potential Drivers on Land Surface Temperature in the Sichuan Basin, China. Remote Sens. 2022, 14, 1292. https:// doi.org/10.3390/rs14051292

Academic Editors: Baojie He, Ayyoob Sharifi, Chi Feng and Jun Yang

Received: 13 February 2022

Accepted: 3 March 2022

Published: 6 March 2022

Publisher's Note: MDPI stays neutral with regard to jurisdictional claims in published maps and institutional affiliations.

Copyright: (c) 2022 by the authors. Licensee MDPI, Basel, Switzerland. This article is an open access article distributed under the terms and conditions of the Creative Commons Attribution (CC BY) license (https:// creativecommons.org/licenses/by/ $4.0 /)$.

\begin{abstract}
Little is known about the seasonal heterogeneity of land surface temperature (LST) and the interaction relationship between potential drivers in Sichuan Basin, China. In this study, based on exploring the spatial heterogeneity of LST in Sichuan Basin, China, multi-source remote sensing data as potential drivers were selected and a Geo-detector model was applied to analyze the main drivers and the interactive relationship between drivers on LST during different seasons. The results showed that the high-temperature areas in Sichuan Basin in different seasons all appeared in the cities near the high mountains on the edge of the basin. This phenomenon was summarized as "sinking heat island" by us. From the driving factors, the biophysical parameters (DEM, SLOPE and NDVI) had the greatest impact on LST in each season, reaching the peak in the transition season. The climate parameters (WIND, HUM, PRE and TEM) and socioeconomic parameters (LIGHT, POP and ROAD) also had a certain impact on LST. The influence of a single landscape parameter (SHDI, PD, LPI, ED and LSI) on LST is limited. From the effect of factor interaction on LST, the interaction of biophysical parameters, climatic parameters and landscape parameters from summer to the transitional season was strengthened obviously, and it showed a downward trend in the winter; in contrast, the socioeconomic parameters showed the opposite characteristics, indicating that the interaction between human activities and other factors affected LST more obviously in the winter. The results of this study are not only valuable for understanding the spatial features of LST but also important for formulating mitigation strategies and sustainable development of urban heat island in Sichuan Basin.
\end{abstract}

Keywords: land surface temperature (LST); urban heat island (UHI) geo-detector; Sichuan Basin; spatial heterogeneity; potential drivers

\section{Introduction}

The increase of population and economic activities worldwide have been promoted by urbanization and industrialization, and a series of environmental problems have been caused by the transformation of these activities on the natural environment, among which the urban heat island (UHI) has attracted much attention [1]. UHI generally refers to the phenomenon that the temperature in urban areas is higher than that in the surrounding suburbs or rural areas [2,3]. UHI has a profound impact on regional climate change (e.g., air pollution and extreme climate) [4,5], residents' health [6], labor productivity [7], ecosystem services [8] and energy consumption [9], which has attracted the attention of researchers in geography, urban planning, ecology and other fields $[10,11]$. Understanding the potential 
drivers of LST is essential to reduce the UHI effect, improve the quality of life of urban residents and promote regional sustainable development [12].

At present, the research foundation of quantitative UHI has been accumulated. Traditionally, urban thermal environments can be identified by comparing urban and suburban temperature differences using atmospheric temperature data observed by ground weather stations. However, the spatial representativeness of meteorological stations and the uncertainty of weather limit its application. In recent years, with the rapid development of Earth observation technology, multisource remote sensing data has been widely used in UHI research $[13,14]$. Remote sensing technology can provide effective urban environmental monitoring means at different spatial scales. Examples include Landsat Thematic Map-per/Enhanced Thematic Mapper+ (TM/ETM+), Moderate-resolution Imaging Spectroradiometer (Modis), Advanced Spaceborne Thermal Emission and radiation (Aster) and Advanced Very-High-Resolution Radiometer (AVHRR) satellite data [15-17]. The development of UHI research has been greatly promoted by the characteristics of high-resolution, multitemporal and multiscale of remote sensing data [18,19].

Although remote sensing data can help researchers depict the spatial and temporal patterns of LST, the purpose of exploring the law is to find solutions. The interaction between LST and influencing factors leads to the spatial heterogeneity of LST. Exploring this relationship can provide insights for reducing UHI phenomenon [20,21]. In general, the factors affecting LST mainly include four aspects: landscape indicators, socioeconomic indicators, climatic conditions and biophysical parameters [22]. Researchers have used a variety of mathematical analysis models to explore the relationship between UHI and spatiotemporal variables [23]. Gao et al. explored the spatial response of urban morphology factors to UHI using a geographically weighted regression model [20]. Based on a Pearson correlation analysis and principal component analysis (PCA), Sun et al. identified the contribution of various driving factors to Hangzhou UHI [24]. Taking Dalian as an example, Guo et al. used the spatial regression model (spatial lag model and spatial error model) to analyze the impact of the urban form on UHI at the community level [25]. These studies have provided valuable reference and basis for exploring the response of UHI to multiple driving factors and formulating mitigation strategies for UHI. However, the spatial characteristics of many influencing factors (e.g., evapotranspiration, vegetation and sky albedo) and their influence on LST changes with the seasons are ignored by many studies [26-28]. Analyzing the spatial characteristics of LST in different seasons and exploring the influence of multiple driving factors on LST are the basis for formulating mitigation measures of reducing the UHI effect. At the same time, most of the existing studies have mainly focused on the influence of a single factor and the determination of a nonlinear spatial relationship among multiple factors, but little is known about their interactions in different seasons $[29,30]$.

The central topography of the basin is low, and the surrounding topography is high The closed topography is not conducive to ventilation and heat dissipation, and the UHI effect is easy to form [31,32]. The Sichuan Basin is one of the most densely populated areas in China, with complex natural and social conditions, and some studies have focused on UHI of a typical city in the basin. For example, the average number of calm days in Chengdu is 240 days a year, and the UHI is becoming more intense during these years [33]. Chongqing, another big city in the Sichuan Basin, has the typical characteristics of a mountain city. The urban spatial form of Chongqing has a significant impact on the urban thermal environment and air quality [34,35]. However, the spatial pattern of different seasons of LST in the Sichuan Basin and the interactive relationship between influencing factors are still unclear. This study is dedicated to bridging this gap. In 2021, the outline of the construction plan for the Two-city Economic Circle in the Chengdu-chongqing region was issued by the Chinese government. The Sichuan Basin is required to take into account the multiple needs of economy, ecology, safety and health. Exploring the mitigation strategies of LST in the Sichuan Basin is of great significance to the regional high-quality and sustainable development. 


\section{Study Area}

Sichuan Basin is located in the south central of the Asian continent $\left(27^{\circ} 50^{\prime}-33^{\circ} 03^{\prime} \mathrm{N}\right.$; $102^{\circ} 97^{\prime}-110^{\circ} 11^{\prime} \mathrm{E}$ ), the eastern part of the Qinghai-Tibet Plateau (Figure 1). According to the classification data of climate zones in China, Sichuan Basin is mainly located in the middle subtropical zone and the north subtropical zone. The climate composition of Sichuan Basin is complex, and there is often heavy rainfall caused by a southwest vortex, valley wind caused by hilly topography and airflow disturbance in the Eastern Tibetan Plateau [23]. At the same time, Sichuan Basin is also one of the most populous regions in China and the world, and it is an important development pole in Western China. The Sichuan Basin includes 15 cities such as Chengdu and 29 districts and counties in Chongqing, with a total area of about $185,000 \mathrm{~km}^{2}$. According to the official data of the National Bureau of Statistics, the permanent population of Sichuan Basin urban agglomeration was 96 million, and the regional GDP was nearly $\$ 0.98$ trillion in 2019. However, under the trend of urban development and construction in recent years, the phenomenon of extreme high temperature in the region has become increasingly prominent. According to the official data of the National Meteorological Administration, when the Sichuan Basin enters the third volt, the daily maximum temperature will reach $36-38^{\circ} \mathrm{C}$, of which the eastern and southern regions can reach more than $38^{\circ} \mathrm{C}$.
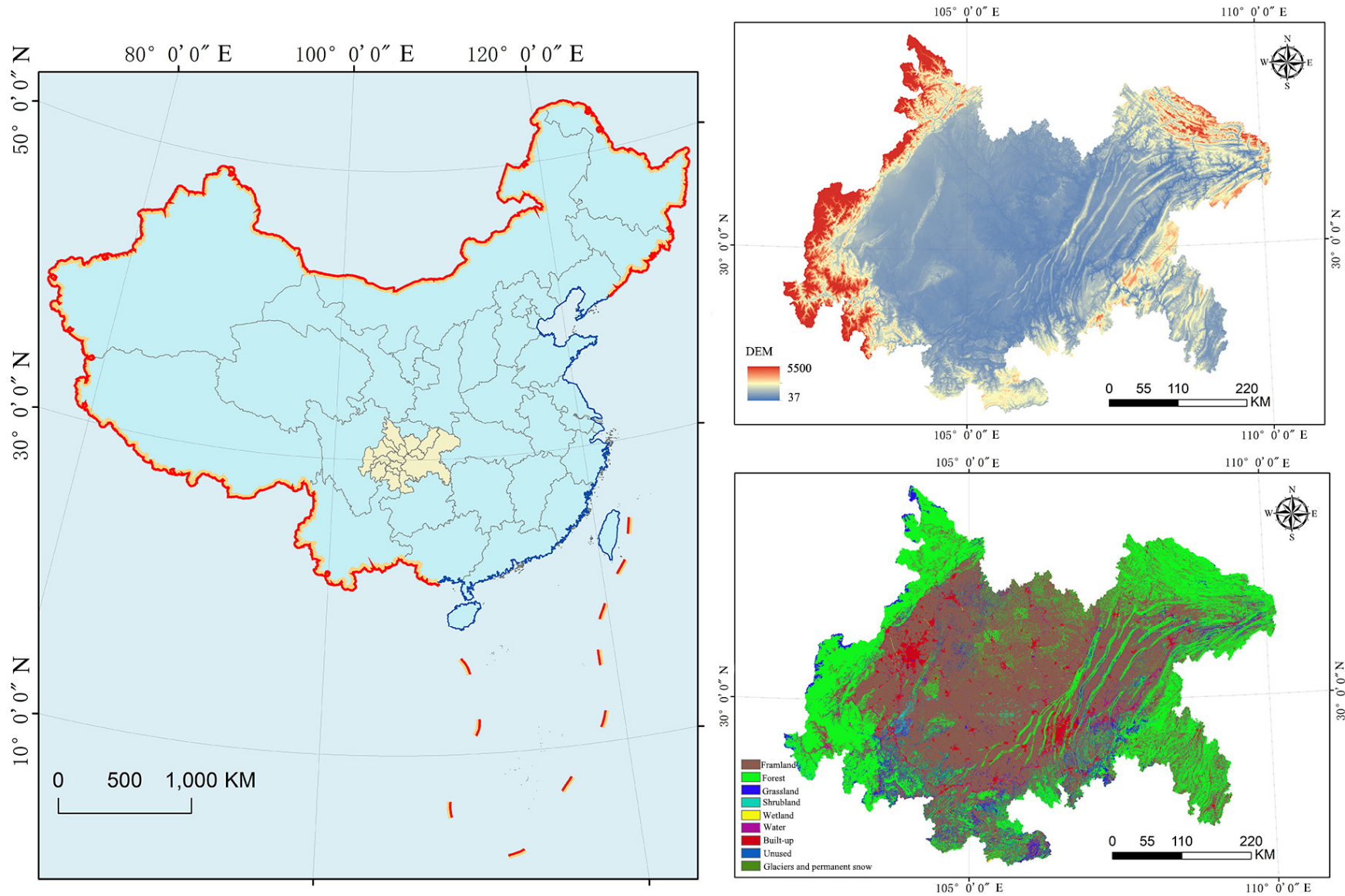

Figure 1. Location, topography and land use of Sichuan Basin. (China's basic base map data comes from the National Basic Geographic Information Center in charge of the Ministry of Natural Resources, https:/ / www.webmap.cn/, accessed on 3 December 2021).

\section{Data and Methods}

\subsection{Data Source and Processing}

Before collecting open access data, we reviewed all relevant service terms of the platform used to ensure that our studies were fully compliant with their agreements. As shown 
in Table 1, fifteen driving factors from four perspectives were selected: biophysical parameters, climatic parameters, socioeconomic parameters and landscape parameters. The DEM, slope and NDVI are used to characterize the biophysical parameters $[19,24]$. The common climatic parameters include wind speed, humidity, precipitation and temperature [14,28]. Night light, population density and road network are commonly used to characterize the socioeconomic parameters [30,32]. The Shannon diversity index, patch density, largest patch index, edge density and landscape shape index are five commonly used landscape indicators as variables to explain landscape parameters $[17,29]$.

Table 1. Potential drivers (biophysical parameters, climatic parameters, socioeconomic parameters and landscape parameters) of LST.

\begin{tabular}{lll}
\hline & \multicolumn{1}{c}{ Potential Drivers } & Abbreviation \\
\hline \multirow{3}{*}{ Biophysical parameters } & Digital Elevation Model & DEM \\
& Slope & SLOPE \\
& NDVI & NDVI \\
\hline \multirow{5}{*}{ Climatic parameters } & Wind speed & WIND \\
& Humidity & HUM \\
& Precipitation & PRE \\
& Temperature & TEM \\
\hline \multirow{3}{*}{ Socio-economic parameters } & Night light & LIGHT \\
& Population density & POP \\
& Road network density & ROAD \\
\hline \multirow{5}{*}{ Landscape parameters } & Shannon Diversity Index & SHDI \\
& Patch Density & PD \\
& Largest Patch Index & LPI \\
& Edge Density & ED \\
& Landscape Shape Index & LSI \\
\hline
\end{tabular}

LST: MODIS remote sensing images covering the Sichuan Basin in 2020 were selected for the study whose data are from LAADSDAAC (https: / /ladsweb.modaps.eosdis.nasa. gov, accessed on 23 December 2021). MODIS is an important sensor mounted on Terra and Aqua satellites. The spatial resolution of the data product is $250-1000 \mathrm{~m}$, which can accurately reflect various information characteristics of the surface and atmosphere. Compared with other remote sensing images, MODIS adopts 8-day composite LST products, which can effectively reduce the impact of cloud cover compared to daily LST products. A large number of studies have shown the accuracy of MODIS LST data [36,37].

Sichuan Basin has obvious subtropical monsoon humid climate characteristics. Referring to Reference [38], the seasons of Sichuan Basin are divided into three types: summer, transition season and winter. As shown in Figure 2, the study area is mainly located in the middle subtropical zone, and very few regions are located in the north subtropic zone. Therefore, we need to consider the temperature of the two climate zones to divide the seasons. In general, the temperature and precipitation of the meteorological stations in the two climatic regions are similar. The average temperature from June to September is relatively high, and the distribution is relatively stable. The fluctuation range of the temperature in these four months is small, so these four months are designated as the summer [39]. Compared with the summer, the average temperature from December to March is lower, especially in February. Therefore, these four months are defined as the winter, while the average temperature from April to May and October to November are highly consistent, and they are often the transitional stage between summer and winter [40]. Therefore, these four months are defined as the transition season. 

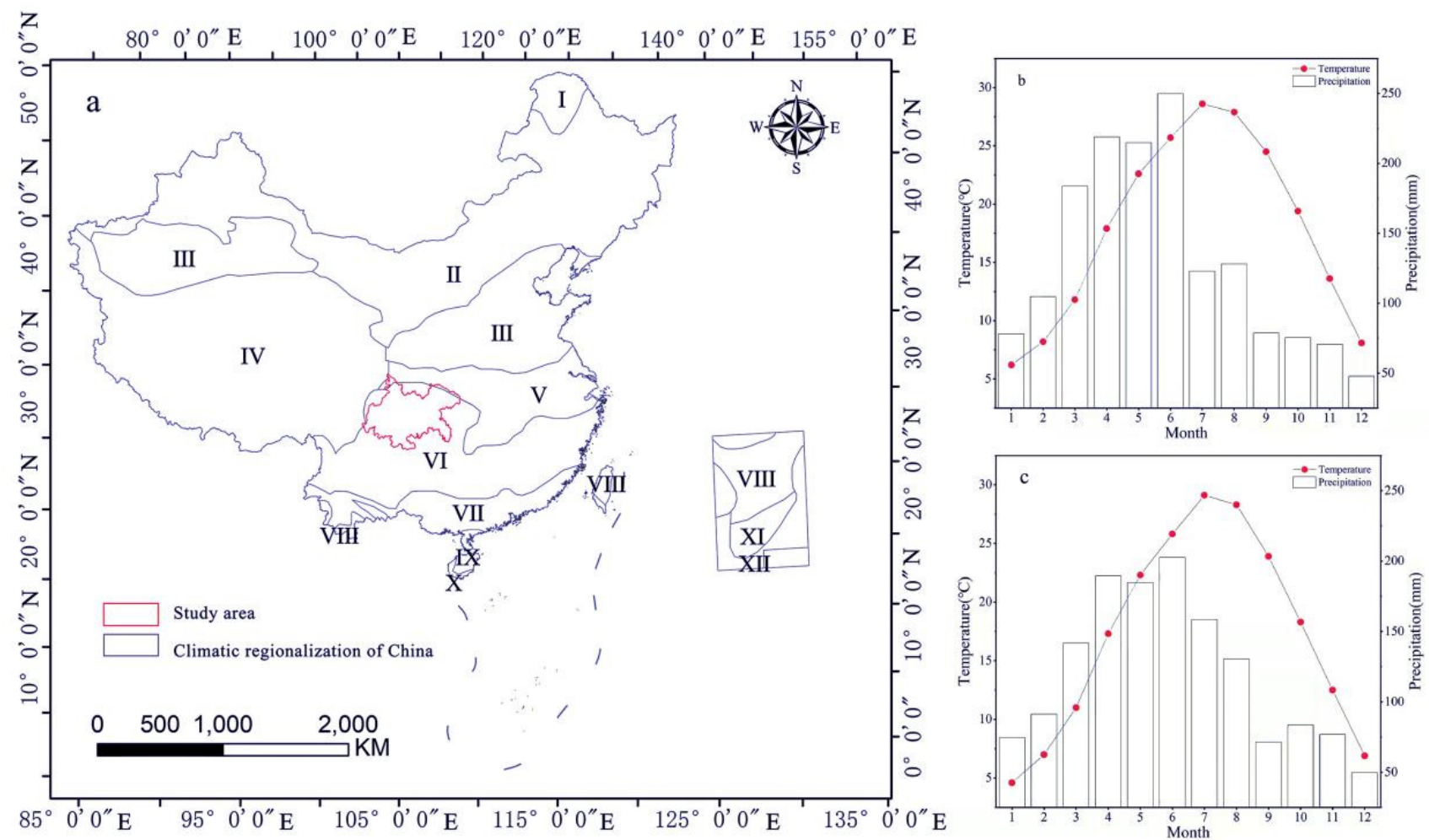

Figure 2. (a) Climate division of the study area, (b) annual cumulative monthly average temperature and precipitation of mid subtropical climate, (c) annual cumulative monthly average temperature and precipitation of north subtropical climate (I. north temperate zone, II. mid-temperate zone, III. south temperate zone, IV. plateau climate region, V. north subtropical zone, VI. middle subtropical zone, VII. south subtropical zone, VIII. edge of tropical region, IX. edge of tropical region, X. mid-tropics zone, XI. south tropic zone and XII. the South China Sea islands).

Potential drivers: DEM data and NDVI data come from a geospatial data cloud platform (http:/ / www.gscloud.cn/, accessed on 24 December 2021). Slope data is obtained from elevation data through ArcGIS 10.6 from the slope tool. Monthly average wind speed, monthly average humidity and monthly mean temperature data are from the National Earth System Science Data Center (http:/ / www.geodata.cn/, accessed on 24 December 2021). The data of road density comes from the nonprofit map service platform open street map (http:/ / www.openstreetmap.org/, accessed on 26 December 2021) through ArcGIS 10.6 preprocessing with the kernel density tool. The population density data were from Worldpop (https: / / www.worldpop.org/, accessed on 25 December 2021), and the night light data were from the world's first professional night light remote sensing satellite "Luojia-1" (http:/ /59.175.109.173:8888/app/login.html, accessed on 25 December 2021). Land use data were from Globeland 30 (http:/ / www.globallandcover.com, accessed on 26 December 2021). Globeland 30 is the first global geographic information public product provided by China to the United Nations. The results after processing with different parameters were shown in Figure 3. 

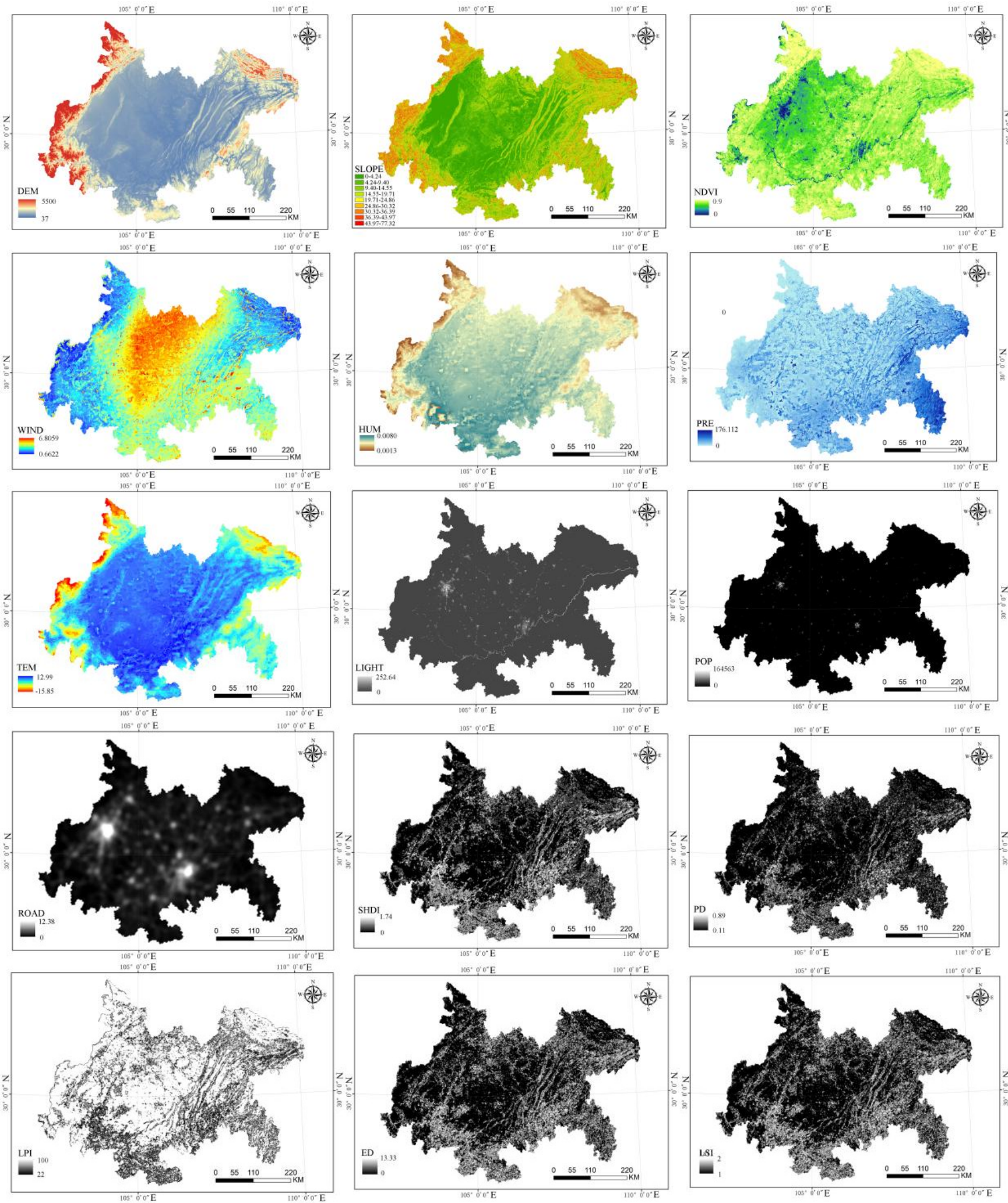

Figure 3. Spatial visualization of the biophysical, climatic, socioeconomic and landscape parameters.

\subsection{Method}

Figure 4 summarizes the method steps of each stage of seasonal comparison of surface temperature and interaction of the driving factors in Sichuan Basin. The following sections will expand and describe the steps of each stage in detail. 


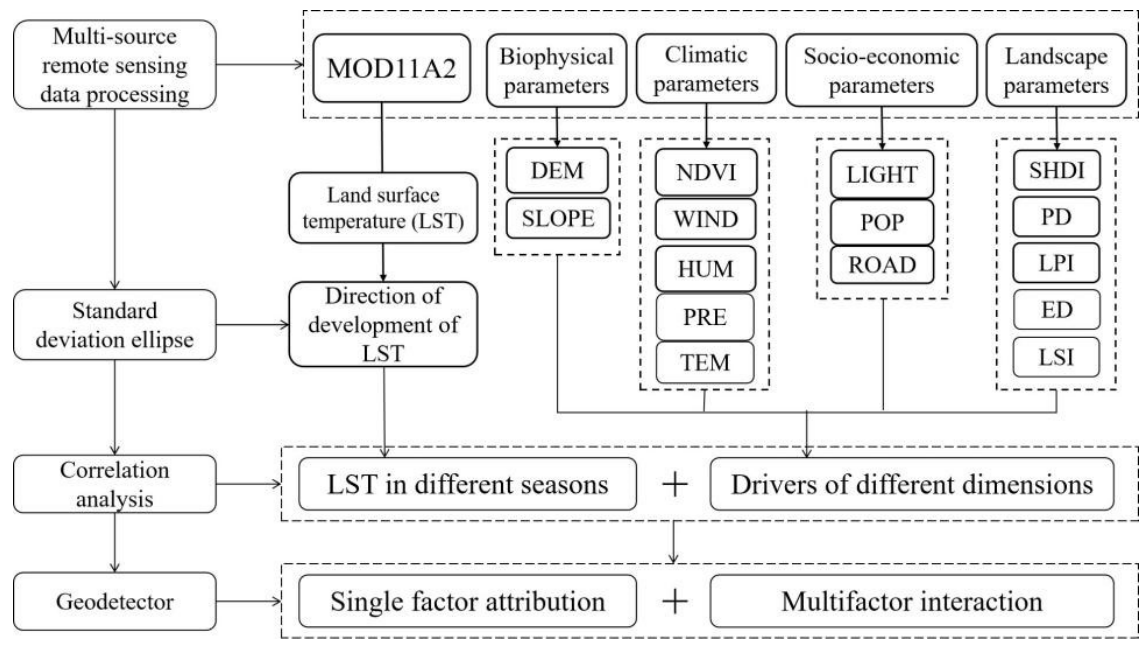

Figure 4. Research framework.

\subsubsection{Landscape Pattern Index}

The landscape pattern index can summarize the information of the landscape pattern [38]. Five representative landscape pattern indices were selected by this study to reflect the characteristics of the landscape structure and spatial configuration (Table 2). The landscape pattern index was calculated by Fragstats 4.2 software.

Table 2. Landscape pattern index and its ecological meaning.

\begin{tabular}{cccc}
\hline Landscape Pattern Index & Calculation Formula & Units & Ecological Meaning \\
\hline SHDI & SHDI $=-\sum_{i=1}^{n} \ln P_{i}$ & None & Reflect the richness of landscape types \\
\hline PD & PD $=\frac{n_{i}}{A}$ & $\mathrm{n} / \mathrm{km}^{2}$ & It reflects the fragmentation of plaque \\
\hline LPI & LPI $=\frac{\max _{j=1}^{m}\left(a_{i j}\right)}{A}$ & Percent & It is helpful to determine the dominant types of landscape \\
\hline ED & $\mathrm{ED}=\frac{E}{A}$ & $\mathrm{~m} / \mathrm{ha}$ & Reflecting the edge effect of landscape \\
\hline LSI & LSI $=\frac{E}{\min E}$ & None & Reflect the shape complexity of the overall landscape \\
\hline
\end{tabular}

\subsubsection{Standard Deviation Ellipse}

A standard deviation ellipse is one of the classical methods to study the directional characteristics of the spatial distribution of geographical elements. The spatial distribution situation and evolution characteristics of the object are described quantitatively by a standard deviation ellipse with the basic parameters of the central point, azimuth angle, long semi-axis and short semi-axis, and the position change and moving direction of the center are identified; the calculation is as follows:

$$
(\overline{\mathrm{A}}, \overline{\mathrm{B}})=\left(\frac{\sum_{i=1}^{n} a_{i} X_{i}}{\sum_{i=1}^{n} X_{i}}, \frac{\sum_{i=1}^{n} b_{i} X_{i}}{\sum_{i=1}^{n} X_{i}}\right)
$$

where $a_{i}$ and $b_{i}$ are the latitude and longitude coordinates of the administrative center of the research unit, respectively, and $X_{i}$ is the value of the locale attribute of the study area, namely the heat island effect of the unit $i .(\overline{\mathrm{A}}, \overline{\mathrm{B}})$ is the study of the LST standard deviation elliptical central point coordinates.

\subsubsection{Correlation Analysis}

We began with the biophysical parameters, climatic parameters, socioeconomic parameters and landscape parameters influencing the distribution of the urban LST and used R 
language and ArcGIS 10.5 to analyze the correlation between them. We chose 100,000 points randomly throughout the sampling tool and then obtained their attribute values. The data were then imported into R language to carry out a Pearson correlation analysis and obtain the Pearson correlation coefficient between each index and the LST.

\subsubsection{Geo-Detector}

Geographic detector (Geo-detector) is a spatial analysis method based on a spatial analysis of variance. This method does not need a linear hypothesis, and for collinearity immunity, it can effectively identify the spatial differentiation of geospatial elements and reveal the driving factors behind it. In recent years, it has been applied to the research of UHI [22]. In this paper, LST in different seasons in the study area is taken as the dependent variable, and the factors affecting LST are independent variables. The "factor detector" and "interaction detector" in the geographic detector are selected to analyze the interpretation degree of each driving factor and factor combination on the spatial heterogeneity of LST in the study area.

(1) Factor detector module: Factor detection detects the impact of each influencing factor on LST spatial differentiation. The higher the $Q$ value, the greater the impact on LST. The factor detection formula is as follows:

$$
\begin{gathered}
q=1-\frac{\sum_{i=1}^{L} N_{i} \sigma_{i}^{2}}{N \sigma^{2}}=1-\frac{\mathrm{SSW}}{\mathrm{SST}} \\
\mathrm{SSW}=\sum_{i=1}^{L} N_{i} \sigma_{i}^{2} \\
\mathrm{SST}=N \sigma^{2}
\end{gathered}
$$

where $i$ represents the stratification of independent or dependent variables, $N_{i}$ represents the number of elements in layer $i, N$ represents the number of elements in the whole domain, $\sigma_{i}^{2}$ denotes the variance of dependent variables in layer $i, \sigma^{2}$ denotes the variance of dependent variables in the whole domain, SSW is the sum of the variances of the different layers and SST is the total variance of the whole region.

(2) Interactive detector module: Interaction detection is used to assess the degree of influence of different combination of driving factors on dependent variables. There are 5 types of interactions between two factors: if the $q$ value of the two-factor interaction is less than any single-factor $q$ value, $(q(A) \cap q(B)<\operatorname{MIN}[q(A), q(B)])$, it is nonlinearweakening. If the two-factor interaction $q$ value between two single-factor $q$ values is $(\operatorname{MIN}[q(A), q(B)]<q(A) \cap q(B)<\operatorname{MAX}[q(A), q(B)])$, it is single-factor nonlinearweakening. If the $q$ value of a two-factor interaction is greater than any single-factor $q$ values, $(q(A) \cap q(B)>\operatorname{MAX}[q(A), q(B)])$, it is a two-factor enhancement. If the $q$ value of the two-factor interaction is equal to the sum of two single-factor $q$ values, $(q(A) \cap q(B)=q(A)+q(B))$, it is independent. If the $q$ value of a two-factor interaction is greater than the sum of two single-factor $q$ values, $(q(A) \cap q(B)>q(A)+q())$, it is a nonlinear enhancement.

\section{Results}

\subsection{Spatial Pattern of LST in Different Seasons}

The surface temperatures of the Sichuan Basin in the summer, transition season and winter 2020 were obtained by supplementing MOD11A2 images of adjacent dates (Figure 5). In the summer, represented by June, July, August and September, the monthly mean surface temperature is $29.25^{\circ} \mathrm{C}$, the maximum is $42.61{ }^{\circ} \mathrm{C}$, the minimum is $3.67{ }^{\circ} \mathrm{C}$ and the standard deviation is $3.45^{\circ}$. In the transition season represented by April, May, October and November, the monthly mean surface temperature is $19.82^{\circ} \mathrm{C}$, the maximum is $42.11^{\circ} \mathrm{C}$, the minimum is $2.01{ }^{\circ} \mathrm{C}$ and the standard deviation is $3.20^{\circ}$. In the winter, represented by December, January, February and March, the monthly mean surface temperature is $9.99{ }^{\circ} \mathrm{C}$, the maximum is $19.15^{\circ} \mathrm{C}$, the minimum is $-15.29^{\circ} \mathrm{C}$ and the standard deviation is $3.96^{\circ}$. 
Both the extreme hot and cold regions of LST in the Sichuan Basin throughout the year are located at the basin margins, with relatively stable temperatures at the center of the basin. Figure 6 and Table 3 show the direction of heat island development in the Sichuan Basin. The greater the oblateness is, the more directional the data. In 2020, the main axis of the spatial development of the heat island remained in the northwest-southeast direction, but the seasonal variations were different. The gravity center of the heat island shifted $67.64 \mathrm{~km}$ to the northwest from the summer to transitional season, and the deflection angle was $12.43^{\circ}$. From the transitional season to the winter, the gravity center of the heat island shifted $16.97 \mathrm{~km}$ to the southeast, with a deflection angle of $2.08^{\circ}$. On the whole, the evolution of the Sichuan Basin heat island is closely related to the spatial development pattern of Chengdu and Chongqing.
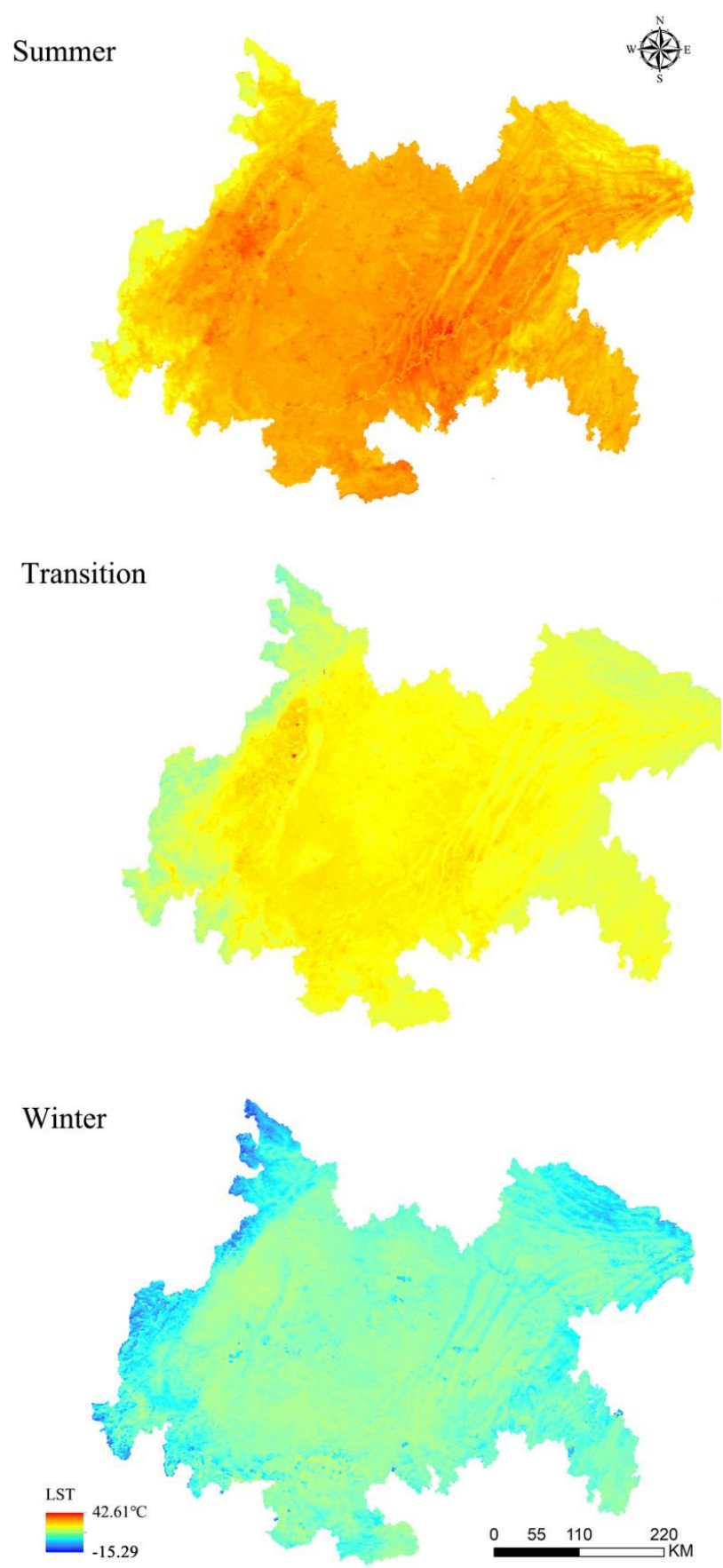

Figure 5. Seasonal spatial variability of LST in the Sichuan Basin. 


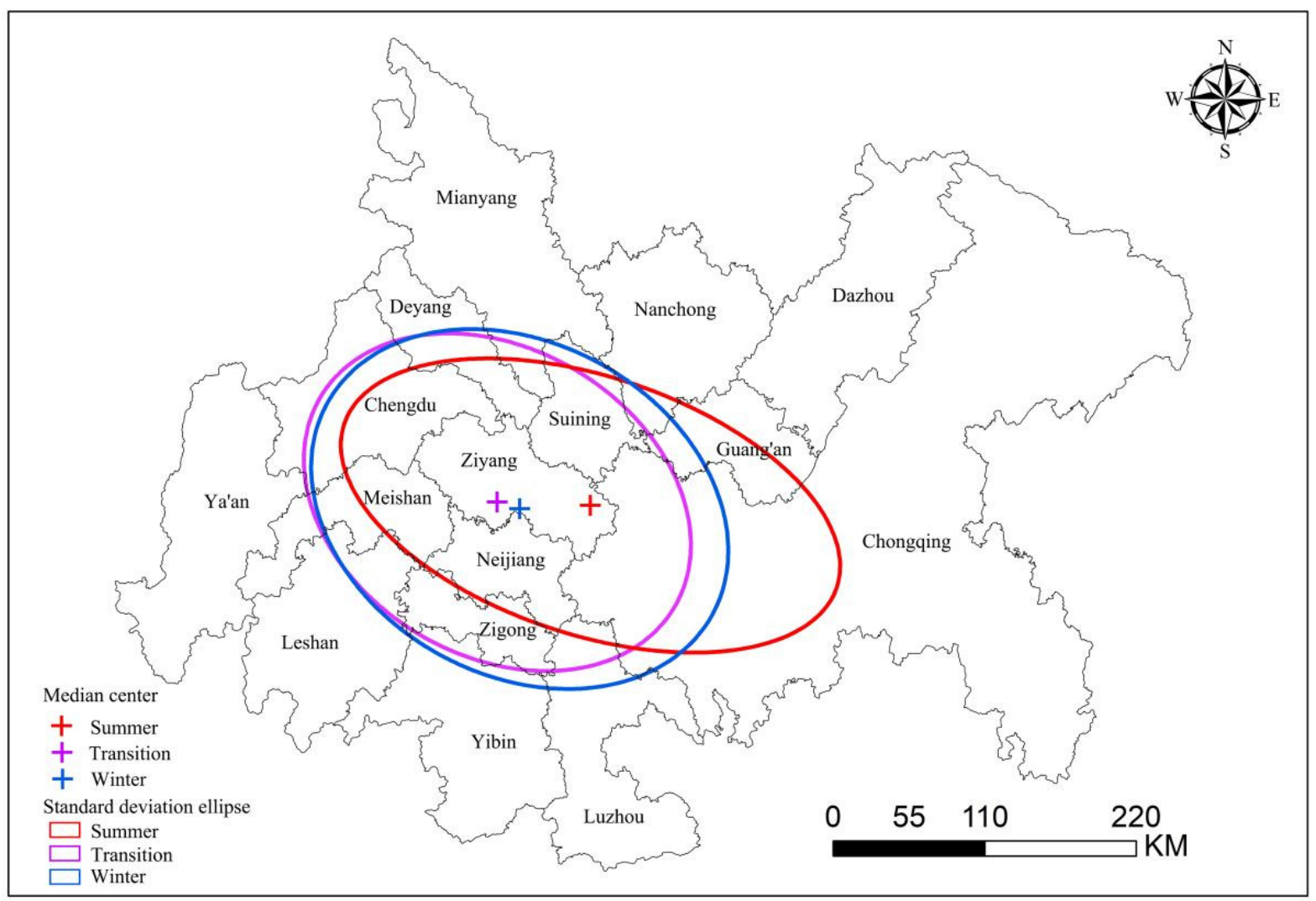

Figure 6. Direction of the development of the Sichuan Basin heat island in 2020.

Table 3. Seasonal spatial variability of LST in the Sichuan Basin.

\begin{tabular}{cccc}
\hline Seasons & Short Axis $\mathbf{( X )}(\mathbf{k m})$ & Long Axis $\mathbf{( Y )}(\mathbf{k m})$ & Rotation Angle $\left.\mathbf{(}^{\circ}\right)$ \\
\hline Summer & $188,344.74$ & $93,517.67$ & 108.31 \\
Transition & $149,353.51$ & $111,409.99$ & 120.74 \\
Winter & $159,421.22$ & $120,565.79$ & 118.66 \\
\hline
\end{tabular}

\subsection{Correlation Analysis between LST and Influencing Factors in Different Seasons}

In order to determine the relevance between LST and the biophysical parameters, climatic parameters, socioeconomic parameters and landscape parameters in different seasons of the Sichuan Basin, a Pearson correlation analysis was used to obtain the positive and negative relationships between the potential driving factors and LST in different seasons. The biophysical parameters and landscape parameters showed significant negative correlations with LST, indicating that the greater the above factors, the lower the corresponding LST. The results showed that the DEM, SLOPE, NDVI, SHDI, PD, LPI, ED and LSI have obvious effects on reducing LST, and all pass the significance test, which is consistent with the results of most previous studies. There is a significant positive correlation between the climatic and socioeconomic parameters and LST, indicating that WIND, HUM, TEM, LIGHT, POP and ROAD are effective in reducing LST; however, LST is influenced by precipitation, which showed a positive correlation in the summer and negative correlation in the winter and transition season (Figure 7). 


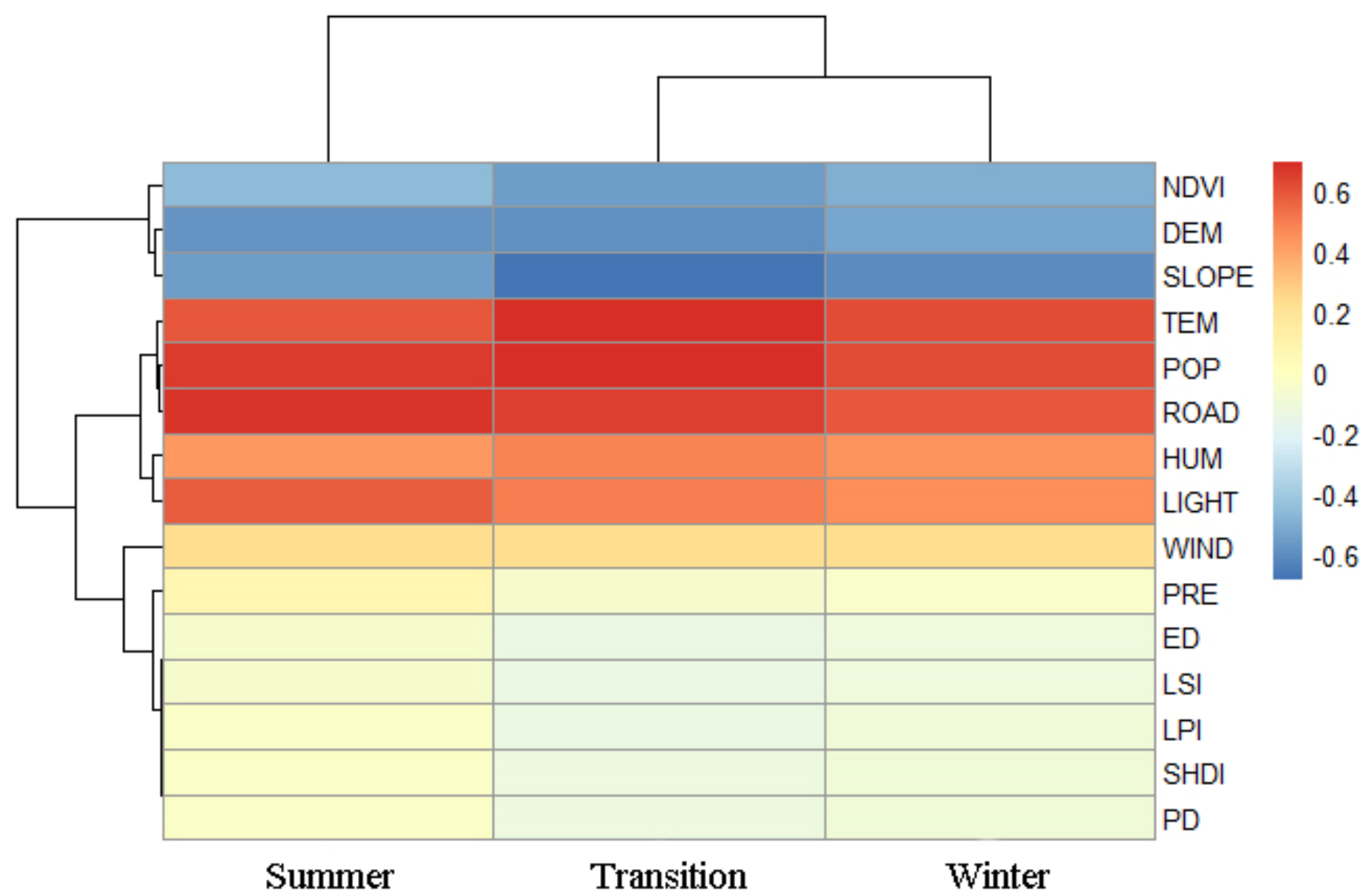

Figure 7. Pearson correlation coefficient of the influencing factors on LST in different seasons.

\subsection{Single Factor Attribution of LST in Different Seasons}

Since the factors of the Geo-detector must be categories rather than values, 15 influencing factors such as biophysical parameters, climate parameters, socioeconomic parameters and landscape parameters are divided into five categories by the natural breakpoint method, so as to detect the main driving factors affecting the surface temperature of the Sichuan Basin. As shown in Figure 8, factor detection is used to analyze the impact of 15 driving factors on the surface temperature intensity in each season ( $q$ value). The results showed that the influencing factors passed the significance test. In the summer, the 15 potential drivers explained the intensity of the surface temperature from large to small: DEM (0.6392) > $\operatorname{TEM}(0.6035)>\operatorname{SLOPE}(0.5932)>\operatorname{HUM}(0.5179)>\operatorname{Pop}(0.5046)>\operatorname{WIND}(0.4353)>\operatorname{ROAD}$ $(0.4202)>\operatorname{LIGHT}(0.4103)>\operatorname{NDVI}(0.3220)>\operatorname{PRE}(0.1839)>\operatorname{LSI}(0.0337)>$ PD $(0.0332)>$ ED (0.0326) > SHDI (0.0308) > LPI (0.0276). The DEM data had the greatest impact on the intensity of the surface temperature in the spring, followed by TEM and SLOPE. Compared with the landscape pattern factor ( $q$ mean 0.0316$)$, the biophysical parameters ( $q$ mean 0.5181 ), socioeconomic parameters ( $q$ mean 0.4450$)$ and climatic parameters ( $q$ mean 0.4351$)$ had great influence on the intensity of the surface temperature in the spring.

In the transition season, the 15 potential drivers explained the surface temperature intensity from large to small: SLOPE (0.8334) > TEM (0.8233) > DEM (0.7978) > HUM $(0.6043)>$ WIND $(0.4149)>$ POP $(0.4132)>$ NDVI $(0.3431)>$ LIGHT $(0.2598)>$ ROAD $(0.2548)>$ PRE $(0.1316)>$ LSI $(0.0436)>$ ED $(0.0405)>$ PD $(0.0296)>$ LPI $(0.0275)>$ SHDI (0.0256). The SLOPE data had the greatest impact on the surface temperature intensity in the transition season, followed by TEM and DEM. The biophysical parameters ( $q$ means 0.6581 ) and climatic parameters ( $q$ means 0.4935 ) had a great influence on the intensity of the surface temperature in the transition season. In the winter, the explanations of 15 potential driving factors for surface temperature intensity were: SLOPE (0.7760) > TEM (0.7739) > 
$\operatorname{DEM}(0.6858)>\operatorname{HUM}(0.5717)>\operatorname{POP}(0.4108)>\operatorname{WIND}(0.3911)>$ NDVI $(0.3784)>\operatorname{LIGHT}$ $(0.2842)>\operatorname{ROAD}(0.2816)>\operatorname{PRE}(0.0922)>\mathrm{ED}(0.0378)>$ LSI $(0.0353)>$ LPI $(0.0245)>$ SHDI $(0.0227)>$ PD (0.0223). Slope data had the greatest impact on the intensity of the surface temperature in the winter, followed by TEM and DEM. Compared with the landscape pattern parameters ( $q$ mean 0.0285$)$, the biophysical parameters ( $q$ mean 0.6134 ) and climatic parameters ( $q$ mean 0.4572 ) had a greater impact on the intensity of the surface temperature in the winter.

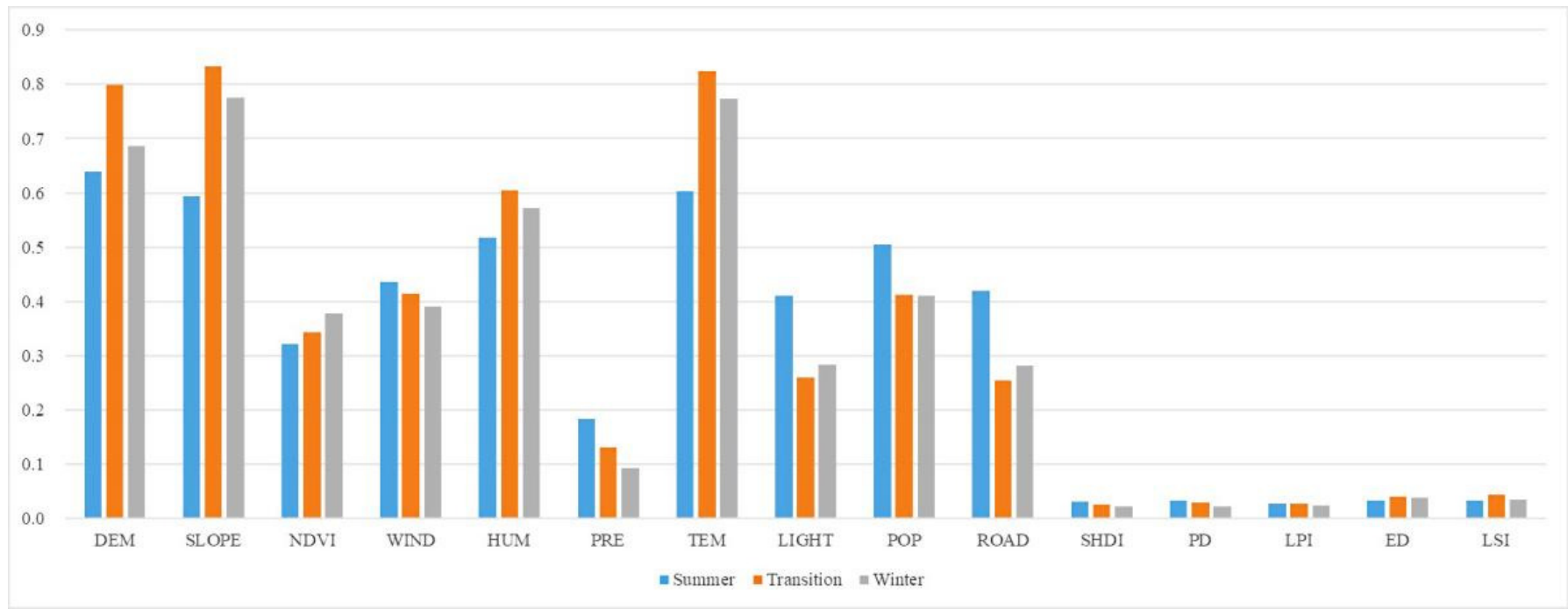

Figure 8. The $q$ values of the influencing factors in different seasons of the Sichuan Basin.

\subsection{Interaction of Influencing Factors of LST in Different Seasons}

The interaction between the driving factors of the surface temperature intensity in 15 cities was tested by interactive detection. The results showed that the interaction $q$ value of each pair of factors was greater than that of the two factors, and the interaction relationship between the driving factors of the surface temperature intensity was synergistically enhanced. The interactive detection results of the summer surface temperature intensity showed that (Figure 9) the maximum $q$ (DEM $\cap$ ROAD) was 0.86, indicating that the interaction between DEM and ROAD had the greatest impact on the summer surface temperature intensity. Meanwhile, $q$ (DEM $\cap$ NDVI) and $q$ (LIGHT $\cap$ POP) both exceeded 0.85 . The interactive detection results of the surface temperature intensity in the transition season showed that the maximum $q$ (SLOPE $\cap$ TEM) was 0.91, indicating that the interaction between SLOPE and TEM had the greatest impact on the surface temperature intensity in the transition season, followed by $q$ (DEM $\cap \mathrm{NDVI}), q$ (SLOPE $\cap \mathrm{HUM}), q$ (TEM $\cap \mathrm{SHDI})$ and $q$ (TEM $\cap \mathrm{PD})$, which were all 0.89. According to the interactive detection results of the winter surface temperature intensity, the maximum values of $q$ (SLOPE $\cap \mathrm{HUM}$ ) and $q$ (TEM $\cap$ PD) were 0.85, indicating that the interactions between SLOPE and HUM and TEM and PD had the greatest impact on the winter surface temperature intensity, followed by $q(\mathrm{TEM} \cap \mathrm{NDVI})$ and $q$ (SLOPE $\cap \mathrm{SHDI})$, which were 0.84 . 

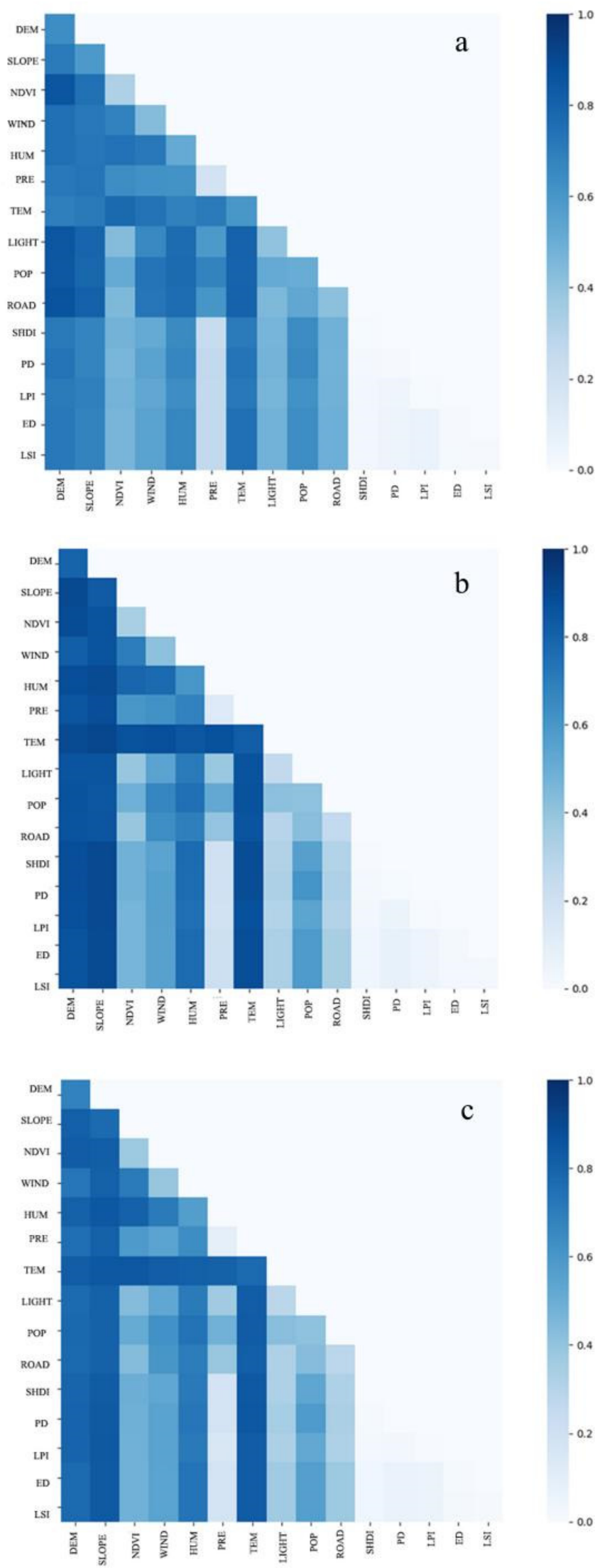

Figure 9. Interaction of the driving factors in different seasons of the Sichuan Basin ((a) summer, (b) transition season and (c) winter). 


\section{Discussion}

\subsection{Spatial Pattern of LST}

The study area is a large area with typical basin topography, including the Tibetan Plateau, Yunnan-Guizhou Plateau, Qin Mountains, Daba Mountains, Hengduan Mountains and other large mountains. The basin bottom can be roughly divided into three parts: parallel mountains and valleys in Eastern Sichuan, hills in Central Sichuan and the Chengdu Plain in Western Sichuan. The results showed that the heat island effect in the Sichuan Basin has obvious spatial differentiation. The relatively humid and cool microclimate environment formed is called cold island. The cold island mainly appears in the mountain area around the basin and the hilly area at the bottom of the basin. The heat island is mainly distributed in the parallel ridge valleys in Eastern Sichuan and the Chengdu Plain in Western Sichuan. In contrast to the overall spatial pattern of LST with "high in the middle and low periphery" in most regions [24,41], the LST in the Sichuan Basin presents the characteristics of "low in the outermost, high in the secondary periphery and low in the middle". From the LST of specific cities, the high-temperature areas are mainly concentrated in most areas of Chengdu and Chongqing; the southeast of Deyang and Mianyang; the north of Luzhou, Yibin and Leshan and the south of Dazhou and Nanchong. Here, there are dense populations, developed industry and agriculture, a large number of impervious water surfaces and cultivated land increasing rapidly, and the terrain of the basin does not easily dissipate heat, forming a large high-temperature area [13,21,42]. The low-value regions are mainly distributed in the central parts of the basin, such as Ziyang, Suining, Neijiang and Zigong, where the vegetation cover is dense; however, the area with flourishing vegetation usually has stronger evapotranspiration, which is characterized by a higher latent heat flux and lower sensible heat flux, thus forming a significant low-temperature area [43-45]. At the same time, the long axis and the short axis of the standard deviation ellipse are used to determine the spatial distribution trend of the high-temperature region, which reflects the spatial variation of the direction of the long axis in the northwest and southeast of the high-temperature region in the study area. In particular, from the summer to the transition season, the major axis of the ellipse decreases, the minor axis increases and the center of gravity shifts to the northwest, indicating that the east-west direction grows faster than the north-south direction. From the transitional season to the winter, the major axis and the minor axis of the ellipse increase, which shows that the high-temperature region of the outer edge of the ellipse grows faster than that of the central one.

\subsection{Influencing Factors of LST}

The current research has discussed the LST distribution pattern of plain cities. Generally speaking, the heat island effect of plain urban agglomeration is mainly affected by the socioeconomic environment [46-48]. The heat island effect basically shows a gradual weakening trend from the central urban area to the suburbs. However, this situation is not necessarily in a closed terrain (such as a basin or valley). Through the research, we found that the city with the hottest surface temperature in the Sichuan Basin is located at the edge of the Sichuan Basin, and the influence of the biophysical factors was greater than that of the other factors. This may be because the thermal air flow of the Sichuan Basin encounters the high mountains at the edge of the basin when it diffuses to the edge, which makes the thermal air flow sink, resulting in the temperature of the cities at the edge of the basin being higher than other regions; this "sinking heat island" has also been discussed in other studies. Most of the landscape parameters have negative correlations with LST, indicating that the landscape pattern can slow down the heat island, which has also been reflected in the research of others [17,40]. Most climatic parameters are positively correlated with LST, indicating that wind speed, humidity and temperature will enhance the heat island [46-49]. Precipitation shows significant seasonal variation characteristics on LST [50], showing a positive correlation in the summer and a negative correlation in the transition season and winter, which is different from the previous research that the total 
precipitation has a negative correlation with the annual LST [31,47]. It may be because the summer precipitation in the Sichuan Basin has a good negative correlation with the heating field of the Qinghai-Tibet Plateau, and the heating field of the Qinghai-Tibet Plateau increased in May. This leads to the decrease of precipitation in the south of the Sichuan Basin, which leads to a positive correlation between summer precipitation and LST in the Sichuan Basin [51]. The role of the socioeconomic activities has significantly enhanced the heat island, because urban expansion and population activities can indirectly increase the thermal energy intensity of LST by reducing vegetation and increasing road, building and energy consumption $[52,53]$.

There are significant seasonal differences in the explanatory powers of the different driving factors on LST $[33,54]$. Specifically, in the hot summer, the ability of the socioeconomic parameters (LIGHT, POP and ROAD) to affect the LST intensity is stronger than that in the transition season and winter. Among them, POP with a $q$ value of 0.4428 has a greater comprehensive influence than ROAD and LIGHT with a figure of almost 0.318 . This shows that POP can fully explain the LST effect, and it can play a certain role in reducing UHI by adjusting the scale and structure of POP [55].

However, the ability of the biophysical parameters (DEM, SLOPE and NDVI) to affect LST is mostly stronger in the transition season, and the interpretation ability of the NDVI to LST is stronger in the winter, which is different from the previous research results, with the highest interpretation of the NDVI in the summer [17], which may be related to the unique vegetation coverage scale and structure formed by the terrain and climate environment of urban mountains in the Sichuan Basin agglomeration. Among them, the comprehensive impact of the SLOPE capability ( $q$ mean 0.7342 ) > comprehensive influence capability of $\operatorname{DEM}(q$ mean 0.7076$)>$ comprehensive capability of NDVI ( $q$ mean 0.3478$)$.

The comprehensive influence of the climate factor parameters on the LST intensity increases from the summer to transition season and then gradually decreases to the winter. Specifically, the changes of humidity and temperature are consistent with the comprehensive influence degree, but the influence ability of the WIND and PRE factors on LST decreases with the decrease of the seasonal temperature, comprehensive influence ability of TEM ( $q$ mean 0.7336$)>$ comprehensive influence ability of HUM ( $q$ mean 0.5646$)>$ comprehensive ability of WIND ( $q$ mean 0.4138$)>$ comprehensive ability of PRE ( $q$ mean value 0.1359$)$. It shows that the spatial variation of LST can be fully explained by TEM, HUM, WIND and PRE. The temperature is consistent with LST, which may be due to the long-wave radiation released from the surface that has an impact on the temperature [56]. High WIND can alleviate UHI by accelerating the temperature exchange $[31,43,57]$. Rainfall is usually accompanied by clouds blocking solar radiation, thus reducing LST, which has also shown in other studies that open rainfall can change soil moisture, which may affect plants and alleviate LST [48].

The overall trend of the influence of the landscape factor parameters on LST increased from the summer to transition season and decreased to the lowest level in the winter. As mentioned by previous scholars, the impact of the landscape factor parameters on LST was extremely limited [58-60], in which the LSI ( $q$ mean 0.0175) $>$ ED $(q$ mean 0.0170) $>$ PD ( $q$ mean 0.0084) > LPI ( $q$ mean 0.0065) > SHDI $(q$ mean 0.0064).

At the same time, the interaction effects of each driving factor on LST also have obvious seasonal differences. The biophysical parameters, climatic parameters and landscape parameters show an obvious interaction-strengthening trend from the summer to transition season, while, with the arrival of winter, they show an obvious downward trend, except the NDVI, LPI and other factors. The socioeconomic parameters show the opposite characteristics; the interaction from the summer to transition season shows a significant downward trend, and the interaction from the transition season to winter shows a significant strengthening trend. It shows that, with the decrease of the seasonal temperature, the impact of human comprehensive activities on LST is more and more significant. The above results are consistent with previous studies [30]. 


\subsection{Research Limitations}

This study still has some limitations and uncertainties. Firstly, we mainly used Geodetector to identify the spatial impact of different influencing factors on LST. Combined with other methods, an evaluation effect may be more reasonable, such as a questionnaire survey, random forest model, geographic weighted regression model and so on [61-63].

Secondly, typical representative potential driving factors from four aspects were mainly selected: biophysical parameters, climatic parameters, socioeconomic parameters and landscape parameters, but the factors affecting LST are varied in different fields. In addition to the possible driving factors considered in this study, other factors may also make non-negligible contributions to LST, such as haze pollution [51], sea-land breeze circulation [64], cloud amount [65], data spatial resolution [66] and other factors. Therefore, the interactions between other factors and LST need to be considered in order to reveal the driving mechanism more comprehensively.

Finally, there was uncertainty of the results due to the data collection time. The diurnal relationship between the valley wind and UHI should be studied on different scales. When the upward heat flow is blown to the topographic edge of the basin, it will be blocked by the mountains and lead to subsidence, so as to increase the heat island temperature in the topographic edge area and form the phenomenon of "sinking heat island". However, the interaction between the daytime "valley wind" and urban environment should be paid attention to, especially the day-night interactions between them. Since the peak can receive more heat during the day while the basin cannot, the temperature of the basin should be lower [67]. At night, however, the mountaintop radiates more heat, making the basin warmer [68].

\section{Conclusions}

Rapid urbanization has led to an obvious rise in LST all over the world, which has caused great harm to human and environmental health. How to effectively reduce LST has become an important proposition of urban ecology. The results show that the joint actions of different influencing factors form the spatial pattern of LST in different periods; the biophysical parameters have the greatest impact on the annual LST (the annual $q$ mean is 0.5965 ), and the annual maximum is in the transition season, followed by the climate parameters (the annual $q$ mean is 0.4620 ) and socioeconomic parameters (the annual $q$ mean value is 0.3599), while the impact of a single landscape parameter on LST is weak, but interactions with other factors have a significant improvement effect. At the same time, there were significant seasonal differences in the interactions of the LST driving factors. The biophysical coefficients, climatic parameters and landscape parameters showed a significant strengthening effect from the summer to transition season, and the interaction increased with the arrival of winter. The interaction between human activities and other factors had a more significant impact on the winter LST. Therefore, rational use of the biophysical parameters and climatic parameters of the Sichuan Basin, especially DEM, SLOPE and TEM, and paying attention to the comprehensive impact of human activities and other factors in the winter are effective measures to alleviate UHI. The results of this study will help urban planners and policymakers make scientific and reasonable decisions and promote the future sustainable development of the Sichuan Basin.

Author Contributions: Z.W.: writing-original draft, data curation, software. D.S.: data curation, software. C.H.: writing-original draft preparation, editing. Y.W.: supervision, writing-review and editing. J.Z.: supervision. All authors have read and agreed to the published version of the manuscript.

Funding: This research was funded by the National Science Foundation for Young Scientists of China, grant numbers 41971162 and 52078245.

Data Availability Statement: All data for this paper are properly cited and referred to in the reference list. 
Conflicts of Interest: The authors declare no conflict of interest.

\section{References}

1. Grimm, N.B.; Faeth, S.H.; Golubiewski, N.E.; Redman, C.L.; Wu, J.; Bai, X.; Briggs, J.M. Global Change and the Ecology of Cities. Science 2008, 319, 756-760. [CrossRef] [PubMed]

2. Oke, T.R. City Size and the Urban Heat Island. Atmos. Environ. 1973, 7, 769-779. [CrossRef]

3. Voogt, J.A.; Oke, T.R. Thermal Remote Sensing of Urban Climates. Remote Sens. Environ. 2003, 86, 370-384. [CrossRef]

4. Liu, Y.; Li, Q.; Yang, L.; Mu, K.; Zhang, M.; Liu, J. Urban Heat Island Effects of Various Urban Morphologies under Regional Climate Conditions. Sci. Total Environ. 2020, 743, 140589. [CrossRef] [PubMed]

5. He, B.-J.; Wang, J.; Liu, H.; Ulpiani, G. Localized Synergies between Heat Waves and Urban Heat Islands: Implications on Human Thermal Comfort and Urban Heat Management. Environ. Res. 2021, 193, 110584. [CrossRef]

6. Tan, J.; Zheng, Y.; Tang, X.; Guo, C.; Li, L.; Song, G.; Zhen, X.; Yuan, D.; Kalkstein, A.J.; Li, F.; et al. The Urban Heat Island and Its Impact on Heat Waves and Human Health in Shanghai. Int. J. Biometeorol. 2010, 54, 75-84. [CrossRef]

7. Zander, K.K.; Botzen, W.J.W.; Oppermann, E.; Kjellstrom, T.; Garnett, S.T. Heat Stress Causes Substantial Labour Productivity Loss in Australia. Nat. Clim. Chang. 2015, 5, 647-651. [CrossRef]

8. Elliot, T.; Babí Almenar, J.; Rugani, B. Modelling the Relationships between Urban Land Cover Change and Local Climate Regulation to Estimate Urban Heat Island Effect. Urban For. Urban Green. 2020, 50, 126650. [CrossRef]

9. Li, X.; Zhou, Y.; Yu, S.; Jia, G.; Li, H.; Li, W. Urban Heat Island Impacts on Building Energy Consumption: A Review of Approaches and Findings. Energy 2019, 174, 407-419. [CrossRef]

10. Yuan, B.; Zhou, L.; Dang, X.; Sun, D.; Hu, F.; Mu, H. Separate and Combined Effects of 3D Building Features and Urban Green Space on Land Surface Temperature. J. Environ. Manag. 2021, 295, 113116. [CrossRef]

11. Yang, J.; Wang, Y.; Xue, B.; Li, Y.; Xiao, X.; Xia, J.C.; He, B. Contribution of Urban Ventilation to the Thermal Environment and Urban Energy Demand: Different Climate Background Perspectives. Sci. Total Environ. 2021, 795, 148791. [CrossRef] [PubMed]

12. Ma, L.; Yang, Z.; Zhou, L.; Lu, H.; Yin, G. Local Climate Zones Mapping Using Object-Based Image Analysis and Validation of Its Effectiveness through Urban Surface Temperature Analysis in China. Build. Environ. 2021, 206, 108348. [CrossRef]

13. He, B.-J.; Zhao, Z.-Q.; Shen, L.-D.; Wang, H.-B.; Li, L.-G. An Approach to Examining Performances of Cool/Hot Sources in Mitigating/Enhancing Land Surface Temperature under Different Temperature Backgrounds Based on Landsat 8 Image. Sustain. Cities Soc. 2019, 44, 416-427. [CrossRef]

14. Yang, J.; Zhan, Y.; Xiao, X.; Xia, J.C.; Sun, W.; Li, X. Investigating the Diversity of Land Surface Temperature Characteristics in Different Scale Cities Based on Local Climate Zones. Urban Clim. 2020, 34, 100700. [CrossRef]

15. Chen, M.; Zhou, Y.; Hu, M.; Zhou, Y. Influence of Urban Scale and Urban Expansion on the Urban Heat Island Effect in Metropolitan Areas: Case Study of Beijing-Tianjin-Hebei Urban Agglomeration. Remote Sens. 2020, 12, 3491. [CrossRef]

16. Imhoff, M.L.; Zhang, P.; Wolfe, R.E.; Bounoua, L. Remote Sensing of the Urban Heat Island Effect across Biomes in the Continental USA. Remote Sens. Environ. 2010, 114, 504-513. [CrossRef]

17. Peng, J.; Jia, J.; Liu, Y.; Li, H.; Wu, J. Seasonal Contrast of the Dominant Factors for Spatial Distribution of Land Surface Temperature in Urban Areas. Remote Sens. Environ. 2018, 215, 255-267. [CrossRef]

18. Zhao, Z.; Sharifi, A.; Dong, X.; Shen, L.; He, B.-J. Spatial Variability and Temporal Heterogeneity of Surface Urban Heat Island Patterns and the Suitability of Local Climate Zones for Land Surface Temperature Characterization. Remote Sens. 2021, 13, 4338. [CrossRef]

19. Yang, J.; Yang, Y.; Sun, D.; Jin, C.; Xiao, X. Influence of Urban Morphological Characteristics on Thermal Environment. Sustain. Cities Soc. 2021, 72, 103045. [CrossRef]

20. Gao, Y.; Zhao, J.; Han, L. Exploring the Spatial Heterogeneity of Urban Heat Island Effect and Its Relationship to Block Morphology with the Geographically Weighted Regression Model. Sustain. Cities Soc. 2022, 76, 103431. [CrossRef]

21. Li, L.; Zha, Y.; Zhang, J. Spatially Non-Stationary Effect of Underlying Driving Factors on Surface Urban Heat Islands in Global Major Cities. Int. J. Appl. Earth Obs. Geoinf. 2020, 90, 102131. [CrossRef]

22. Xiang, Y.; Huang, C.; Huang, X.; Zhou, Z.; Wang, X. Seasonal Variations of the Dominant Factors for Spatial Heterogeneity and Time Inconsistency of Land Surface Temperature in an Urban Agglomeration of Central China. Sustain. Cities Soc. 2021, 75, 103285. [CrossRef]

23. Liu, H.; Huang, B.; Zhan, Q.; Gao, S.; Li, R.; Fan, Z. The Influence of Urban Form on Surface Urban Heat Island and Its Planning Implications: Evidence from 1288 Urban Clusters in China. Sustain. Cities Soc. 2021, 71, 102987. [CrossRef]

24. Sun, D.; Hu, C.; Wang, Y.; Wang, Z.; Zhang, J. Examining Spatio-Temporal Characteristics of Urban Heat Islands and Factors Driving Them in Hangzhou, China. IEEE J. Sel. Top. Appl. Earth Obs. Remote Sens. 2021, 14, 8316-8325. [CrossRef]

25. Guo, A.; Yang, J.; Xiao, X.; Xia, J.; Jin, C.; Li, X. Influences of Urban Spatial Form on Urban Heat Island Effects at the Community Level in China. Sustain. Cities Soc. 2020, 53, 101972. [CrossRef]

26. Haashemi, S.; Weng, Q.; Darvishi, A.; Alavipanah, S. Seasonal Variations of the Surface Urban Heat Island in a Semi-Arid City. Remote Sens. 2016, 8, 352. [CrossRef]

27. Manoli, G.; Fatichi, S.; Bou-Zeid, E.; Katul, G.G. Seasonal Hysteresis of Surface Urban Heat Islands. Proc. Natl. Acad. Sci. USA 2020, 117, 7082-7089. [CrossRef] 
28. Yang, J.; Jin, S.; Xiao, X.; Jin, C.; Xia, J.C.; Li, X.; Wang, S. Local Climate Zone Ventilation and Urban Land Surface Temperatures: Towards a Performance-Based and Wind-Sensitive Planning Proposal in Megacities. Sustain. Cities Soc. $2019,47,101487$. [CrossRef]

29. Ren, Y.; Deng, L.-Y.; Zuo, S.-D.; Song, X.-D.; Liao, Y.-L.; Xu, C.-D.; Chen, Q.; Hua, L.-Z.; Li, Z.-W. Quantifying the Influences of Various Ecological Factors on Land Surface Temperature of Urban Forests. Environ. Pollut. 2016, 216, 519-529. [CrossRef]

30. Feng, R.; Wang, F.; Wang, K.; Wang, H.; Li, L. Urban Ecological Land and Natural-Anthropogenic Environment Interactively Drive Surface Urban Heat Island: An Urban Agglomeration-Level Study in China. Environ. Int. 2021, 157, 106857. [CrossRef]

31. Sarangi, C.; Tripathi, S.N.; Qian, Y.; Kumar, S.; Ruby Leung, L. Aerosol and Urban Land Use Effect on Rainfall Around Cities in Indo-Gangetic Basin From Observations and Cloud Resolving Model Simulations. J. Geophys. Res. Atmos. 2018, 123, 3645-3667. [CrossRef]

32. Guo, J.; Han, G.; Xie, Y.; Cai, Z.; Zhao, Y. Exploring the Relationships between Urban Spatial Form Factors and Land Surface Temperature in Mountainous Area: A Case Study in Chongqing City, China. Sustain. Cities Soc. 2020, 61, 102286. [CrossRef]

33. Wu, S.; Yang, H.; Luo, P.; Luo, C.; Li, H.; Liu, M.; Ruan, Y.; Zhang, S.; Xiang, P.; Jia, H.; et al. The Effects of the Cooling Efficiency of Urban Wetlands in an Inland Megacity: A Case Study of Chengdu, Southwest China. Build. Environ. 2021, 204, 108128. [CrossRef]

34. Luo, X.; Yang, J.; Sun, W.; He, B. Suitability of Human Settlements in Mountainous Areas from the Perspective of Ventilation: A Case Study of the Main Urban Area of Chongqing. J. Clean. Prod. 2021, 310, 127467. [CrossRef]

35. Rigo, G.; Parlow, E.; Oesch, D. Validation of Satellite Observed Thermal Emission with In-Situ Measurements over an Urban Surface. Remote Sens. Environ. 2006, 104, 201-210. [CrossRef]

36. Wan, Z. New Refinements and Validation of the MODIS Land-Surface Temperature/Emissivity Products. Remote Sens. Environ. 2008, 112, 59-74. [CrossRef]

37. Chen, T.; Feng, Z.; Zhao, H.; Wu, K. Identification of Ecosystem Service Bundles and Driving Factors in Beijing and Its Surrounding Areas. Sci. Total Environ. 2020, 711, 134687. [CrossRef]

38. Zhou, W.; Huang, G.; Cadenasso, M.L. Does Spatial Configuration Matter? Understanding the Effects of Land Cover Pattern on Land Surface Temperature in Urban Landscapes. Landsc. Urban Plan. 2011, 102, 54-63. [CrossRef]

39. Hu, Y.; Hou, M.; Jia, G.; Zhao, C.; Zhen, X.; Xu, Y. Comparison of Surface and Canopy Urban Heat Islands within Megacities of Eastern China. ISPRS J. Photogramm. Remote Sens. 2019, 156, 160-168. [CrossRef]

40. Liu, Y.; Peng, J.; Wang, Y. Efficiency of Landscape Metrics Characterizing Urban Land Surface Temperature. Landsc. Urban Plan. 2018, 180, 36-53. [CrossRef]

41. Zhou, D.; Zhao, S.; Liu, S.; Zhang, L.; Zhu, C. Surface Urban Heat Island in China's 32 Major Cities: Spatial Patterns and Drivers. Remote Sens. Environ. 2014, 152, 51-61. [CrossRef]

42. Wang, L.; Chen, L. The Impact of New Transportation Modes on Population Distribution in Jing-Jin-Ji Region of China. Sci. Data 2018, 5, 170204. [CrossRef] [PubMed]

43. Yang, Q.; Huang, X.; Tang, Q. Irrigation Cooling Effect on Land Surface Temperature across China Based on Satellite Observations. Sci. Total Environ. 2020, 705, 135984. [CrossRef]

44. Weng, Q.; Lu, D.; Schubring, J. Estimation of Land Surface Temperature-Vegetation Abundance Relationship for Urban Heat Island Studies. Remote Sens. Environ. 2004, 89, 467-483. [CrossRef]

45. Ren, J.; Yang, J.; Zhang, Y.; Xiao, X.; Xia, J.C.; Li, X.; Wang, S. Exploring Thermal Comfort of Urban Buildings Based on Local Climate Zones. J. Clean. Prod. 2022, 340, 130744. [CrossRef]

46. Sun, R.; Lü, Y.; Yang, X.; Chen, L. Understanding the Variability of Urban Heat Islands from Local Background Climate and Urbanization. J. Clean. Prod. 2019, 208, 743-752. [CrossRef]

47. Zhou, D.; Zhang, L.; Li, D.; Huang, D.; Zhu, C. Climate-Vegetation Control on the Diurnal and Seasonal Variations of Surface Urban Heat Islands in China. Environ. Res. Lett. 2016, 11, 074009. [CrossRef]

48. Yao, R.; Wang, L.; Huang, X.; Zhang, W.; Li, J.; Niu, Z. Interannual Variations in Surface Urban Heat Island Intensity and Associated Drivers in China. J. Environ. Manag. 2018, 222, 86-94. [CrossRef]

49. Gedzelman, S.D.; Austin, S.; Cermak, R.; Stefano, N.; Partridge, S.; Quesenberry, S.; Robinson, D.A. Mesoscale Aspects of the Urban Heat Island around New York City. Theor. Appl. Climatol. 2003, 75, 29-42. [CrossRef]

50. Manoli, G.; Fatichi, S.; Schläpfer, M.; Yu, K.; Crowther, T.W.; Meili, N.; Burlando, P.; Katul, G.G.; Bou-Zeid, E. Magnitude of Urban Heat Islands Largely Explained by Climate and Population. Nature 2019, 573, 55-60. [CrossRef]

51. Cao, C.; Lee, X.; Liu, S.; Schultz, N.; Xiao, W.; Zhang, M.; Zhao, L. Urban Heat Islands in China Enhanced by Haze Pollution. Nat. Commun. 2016, 7, 12509. [CrossRef] [PubMed]

52. Connors, J.P.; Galletti, C.S.; Chow, W.T.L. Landscape Configuration and Urban Heat Island Effects: Assessing the Relationship between Landscape Characteristics and Land Surface Temperature in Phoenix, Arizona. Landsc. Ecol. 2013, 28, 271-283. [CrossRef]

53. Buyantuyev, A.; Wu, J. Urban Heat Islands and Landscape Heterogeneity: Linking Spatiotemporal Variations in Surface Temperatures to Land-Cover and Socioeconomic Patterns. Landsc. Ecol. 2010, 25, 17-33. [CrossRef]

54. Yao, L.; Xu, Y.; Zhang, B. Effect of Urban Function and Landscape Structure on the Urban Heat Island Phenomenon in Beijing, China. Landsc. Ecol. Eng. 2019, 15, 379-390. [CrossRef]

55. Li, Y.; Sun, Y.; Li, J.; Gao, C. Socioeconomic Drivers of Urban Heat Island Effect: Empirical Evidence from Major Chinese Cities. Sustain. Cities Soc. 2020, 63, 102425. [CrossRef] 
56. Wang, W.; Yao, X.; Shu, J. Air Advection Induced Differences between Canopy and Surface Heat Islands. Sci. Total Environ. 2020, 725, 138120. [CrossRef]

57. Zhou, D.; Bonafoni, S.; Zhang, L.; Wang, R. Remote Sensing of the Urban Heat Island Effect in a Highly Populated Urban Agglomeration Area in East China. Sci. Total Environ. 2018, 628-629, 415-429. [CrossRef]

58. Chen, A.; Yao, L.; Sun, R.; Chen, L. How Many Metrics Are Required to Identify the Effects of the Landscape Pattern on Land Surface Temperature? Ecol. Indic. 2014, 45, 424-433. [CrossRef]

59. Li, W.; Cao, Q.; Lang, K.; Wu, J. Linking Potential Heat Source and Sink to Urban Heat Island: Heterogeneous Effects of Landscape Pattern on Land Surface Temperature. Sci. Total Environ. 2017, 586, 457-465. [CrossRef]

60. Zhou, D.; Xiao, J.; Bonafoni, S.; Berger, C.; Deilami, K.; Zhou, Y.; Frolking, S.; Yao, R.; Qiao, Z.; Sobrino, J. Satellite Remote Sensing of Surface Urban Heat Islands: Progress, Challenges, and Perspectives. Remote Sens. 2018, 11, 48. [CrossRef]

61. He, B.-J.; Zhao, D.; Xiong, K.; Qi, J.; Ulpiani, G.; Pignatta, G.; Prasad, D.; Jones, P. A Framework for Addressing Urban Heat Challenges and Associated Adaptive Behavior by the Public and the Issue of Willingness to Pay for Heat Resilient Infrastructure in Chongqing, China. Sustain. Cities Soc. 2021, 75, 103361. [CrossRef]

62. Zhao, D.; Arshad, M.; Wang, J.; Triantafilis, J. Soil Exchangeable Cations Estimation Using Vis-NIR Spectroscopy in Different Depths: Effects of Multiple Calibration Models and Spiking. Comput. Electron. Agric. 2021, 182, 105990. [CrossRef]

63. Zhao, D.; Wang, J.; Zhao, X.; Triantafilis, J. Clay Content Mapping and Uncertainty Estimation Using Weighted Model Averaging. CATENA 2022, 209, 105791. [CrossRef]

64. Shi, T.; Hu, Z.; Shi, Z.; Guo, L.; Chen, Y.; Li, Q.; Wu, G. Geo-Detection of Factors Controlling Spatial Patterns of Heavy Metals in Urban Topsoil Using Multi-Source Data. Sci. Total Environ. 2018, 643, 451-459. [CrossRef] [PubMed]

65. Schatz, J.; Kucharik, C.J. Seasonality of the Urban Heat Island Effect in Madison, Wisconsin. J. Appl. Meteorol. Climatol. 2014, 53, 2371-2386. [CrossRef]

66. Zhou, W.; Qian, Y.; Li, X.; Li, W.; Han, L. Relationships between Land Cover and the Surface Urban Heat Island: Seasonal Variability and Effects of Spatial and Thematic Resolution of Land Cover Data on Predicting Land Surface Temperatures. Landsc. Ecol. 2014, 29, 153-167. [CrossRef]

67. McFeeters, S.K. The Use of the Normalized Difference Water Index (NDWI) in the Delineation of Open Water Features. Int. J. Remote Sens. 1996, 17, 1425-1432. [CrossRef]

68. He, B.-J.; Ding, L.; Prasad, D. Wind-Sensitive Urban Planning and Design: Precinct Ventilation Performance and Its Potential for Local Warming Mitigation in an Open Midrise Gridiron Precinct. J. Build. Eng. 2020, 29, 101145. [CrossRef] 